\begin{tabular}{ll|l}
\cline { 2 - 3 } & \multicolumn{2}{l}{ Intervent Neurol 2012;1:164-170 } \\
\cline { 2 - 3 } & $\begin{array}{l}\text { DOI: 10.1159/000353124 2013 S. Karger AG, Basel } \\
\text { Published online: July 10, 2013 }\end{array}$ & $\begin{array}{l}\text { (c) } \\
\text { 1664-9737/12/0014-0164\$38.00/0 } \\
\text { www.karger.com/ine }\end{array}$ \\
\hline
\end{tabular}

\title{
Review
}

\section{A Systematic Review of Endovascular Management of Internal Carotid Artery Dissections}

\author{
Huang Xianjun Zhou Zhiming \\ Department of Neurology, Yijishan Hospital of Wannan Medical College, Wuhu, China
}

\section{Key Words}

Endovascular intervention · Internal carotid artery dissection · Stenting

\begin{abstract}
Background: We conducted a review of the safety and outcomes of endovascular intervention in patients with internal carotid artery dissection (ICAD). Summary: A literature review was performed. PubMed and Medline databases were searched from inception to September 2012 with the key words 'carotid artery' (title), 'dissection' (title) and 'endovascular' (title/abstract). All studies were included which reported outcomes of endovascular intervention in ICAD and provided information about technical and clinical results. After screening, we included 23 articles. In total, 201 patients (128 male and 73 female) were included in the eligible studies. The mean age was 46.7 years (range 13-83 years). Of the 201 patients, the causes of the carotid dissections were traumatic in 69 (34.3\%), spontaneous in 115 (57.2\%) and iatrogenic in 17 (8.5\%). The technical success rate was $99.1 \%$. The overall rate of major cardiovascular events in the perioperative period was $4 \%$. No procedure-related deaths occurred. Imaging follow-up data (mean follow-up time 16.5 months) demonstrated that only $3.3 \%$ of patients had intimal hyperplasia or in-stent restenosis or occlusion of a treated vessel. Clinical follow-up data (mean follow-up period 20.9 months) showed that only $2.1 \%$ of patients had a recurrent transient ischemic attack in the territory of the treated vessel. Key Messages: Endovascular intervention with stenting or stent-graft-supported angioplasty in selected patients with ICAD is promising. However, further evaluation is warranted to provide more evidence to support the feasibility of endovascular procedures in treating ICAD.
\end{abstract}




\section{Introduction}

Internal carotid artery dissection (ICAD) is defined as intimal splitting due to a variety of etiologies, which may be spontaneous, traumatic or iatrogenic in origin, allowing blood to enter into the cleft in the artery wall and enlarge the split, resulting in a mural hematoma or aneurysmal dilatation [1-3]. Although ICAD is an uncommon entity and the clinical presentations are often benign, dissections are the most common cause of stroke in young patients, accounting for about $10 \%$ of strokes in this subset [1].

Results from a previous study indicated that in patients with ICAD, thromboembolism is the essential mechanism of subsequent stroke [4]. Based on these results, antithrombotic drugs such as anticoagulatives or antiplatelets were considered the first-line treatment option [5]. However, antithrombotic treatment may be contraindicated in some patients because of the risk of bleeding. In some patients with persistent or progressive symptoms, the expansion of concomitant pseudoaneurysms is an important reason for the deterioration of neurologic symptoms and aggravation of hemodynamic brain ischemia. These patients may fail medical treatment [6]. Previous studies revealed that annual neurologic morbidity rates under long-term medical therapy have been reported to be $8-12 \%[5,7]$. Therefore, an alternative therapeutic approach to achieve sufficient restoration of the vessel lumen is sometimes needed.

In 1997, Matsuura et al. [8] reported the first patient with ICAD who was successfully treated with stent deployment. They considered that stenting may be an appropriate approach to ICAD when medical measures do not prevent progressive events. Since then, more and more studies have showed that endovascular management may be effective in selected patients with ICAD [9-11]. Nevertheless, endovascular management in ICAD has not been thoroughly studied. The safety and outcome of stenting in ICAD is still unclear. Hence, we conducted a systematic literature review to investigate this entity.

\section{Methods}

PubMed and Medline databases were searched from inception to September 2012 with the key words 'carotid artery' (title), 'dissection' (title) and 'endovascular' (title/abstract). In addition, reference lists of all included articles were examined for further relevant references. The full text of these articles was retrieved.

Studies were included if they met the following criteria: (1) ICAD was diagnosed with the help of enhanced computed tomography, magnetic resonance imaging or angiography; (2) endovascular reconstruction was performed; (3) the lesion involved the internal carotid artery, including the extracranial carotid artery and intracranial carotid artery, and (4) the mean follow-up period was not less than 6 months [12]. Studies were excluded due to the following circumstances: (1) no outcome data or (2) use of thrombolytic therapy [12].

For each study, we extracted and analyzed the following data: patient characteristics (number of patients, age, sex, causes of ICAD, features of dissection), indications for endovascular treatment, complications in the perioperative period and the clinical and imaging follow-up data.

All numeric values are stated as medians, with minimum and maximum values in parentheses. All percentages were calculated by using the total number of reported patients as $100 \%$ for each parameter.

\section{Results}

The literature search yielded 46 publications. After screening, we included 23 articles. Studies were excluded if there was use of thrombolytic therapy $(n=5)$, mean follow-up of less than 6 months $(n=9)$ or lack of outcome reporting $(n=9)$. 
Table 1. Characteristics of patients in the review analysis

\begin{tabular}{|c|c|c|c|c|c|}
\hline Authors & Year & $\begin{array}{l}\text { Number of } \\
\text { patients }\end{array}$ & ICAD etiology & $\begin{array}{l}\text { Dissection } \\
\text { site }\end{array}$ & $\begin{array}{l}\text { Follow-up } \\
\text { months }\end{array}$ \\
\hline Matsuura et al. [8] & 1997 & 1 & $\mathrm{~T}$ & Ex-ICA & 12 \\
\hline Malek et al. [9] & 2000 & 10 & $T(2)+S(5)+I(3)$ & Ex-ICA & 16.5 \\
\hline Tseng et al. [13] & 2003 & 1 & $\mathrm{~S}$ & Ex-ICA & 9 \\
\hline Cohen et al. [14] & 2003 & 3 & $\mathrm{~S}$ & Ex-ICA & 10 \\
\hline Fanelli et al. [15] & 2004 & 1 & $\mathrm{~T}$ & Ex-ICA & 13 \\
\hline Assadian et al. [16] & 2004 & 6 & $\mathrm{~S}$ & Ex-ICA & 38.3 \\
\hline Biggs et al. [17] & 2004 & 1 & $\mathrm{~S}$ & Ex-ICA & 19 \\
\hline Cohen et al. [18] & 2005 & 10 & $\mathrm{~T}$ & Ex-ICA & 16 \\
\hline Kadkhodayan et al. [19] & 2005 & 26 & $T(9)+S(8)+I(9)$ & Ex-ICA & 14.6 \\
\hline Biondi et al. [20] & 2005 & 1 & $\mathrm{~S}$ & Ex-ICA & 8 \\
\hline Briganti et al. [21] & 2005 & 1 & $\mathrm{~S}$ & Ex-ICA & 24 \\
\hline Edgell et al. [22] & 2005 & 7 & $\mathrm{~S}$ & Ex-ICA & 14 \\
\hline Nakagawa et al. [23] & 2007 & 1 & $\mathrm{~T}$ & Ex-ICA & 72 \\
\hline Fava et al. [24] & 2008 & 12 & $\mathrm{~T}(1)+\mathrm{S}(11)$ & Ex-ICA & 24 \\
\hline Schulte et al. [25] & 2008 & 7 & $\mathrm{~T}(2)+\mathrm{I}(5)$ & Ex-ICA & 25 \\
\hline Surdell et al. [26] & 2009 & 1 & $\mathrm{~S}$ & In-ICA & 8 \\
\hline Binning et al. [27] & 2010 & 1 & $\mathrm{~T}$ & In-ICA & 6 \\
\hline Cohen et al. [28] & 2010 & 2 & $\mathrm{~S}$ & Ex-ICA & 21 \\
\hline Smith et al. [29] & 2010 & 2 & $\mathrm{~S}$ & In-ICA & 30 \\
\hline Jeon et al. [30] & 2010 & 8 & $\mathrm{~T}(4)+\mathrm{S}(4)$ & Ex-ICA (5) + In-ICA (3) & 21 \\
\hline Ohta et al. [11] & 2011 & 43 & $T(12)+S(31)$ & Ex-ICA (27) + In-ICA (16) & 19.2 \\
\hline Yin et al. [10] & 2011 & 33 & $T(2)+S(31)$ & Ex-ICA (32) + In-ICA (1) & 27.6 \\
\hline Cohen et al. [6] & 2012 & 23 & $\mathrm{~T}$ & Ex-ICA & 28.7 \\
\hline
\end{tabular}

$\mathrm{T}$ = Traumatic; $\mathrm{S}=$ spontaneous; $\mathrm{I}$ = iatrogenic; $\mathrm{Ex}-\mathrm{ICA}$ = extracranial internal carotid artery; In-ICA = intracranial internal carotid artery.

\section{Patient Characteristics}

In total, 201 patients (128 male and 73 female) were included in the eligible studies. The mean age was 46.7 years (range 13-83 years). Of the 201 patients, the causes of the carotid dissections were traumatic in 69 (34.3\%), spontaneous in $115(57.2 \%)$ and iatrogenic in 17 (8.5\%). Twenty-four patients (11.9\%) had intracranial dissections. Eleven patients (5.5\%) showed bilateral ICAD. Thirty-eight patients (18.9\%) showed pseudoaneurysm formation (table 1).

\section{Indications for Endovascular Treatment}

In the 201 patients, the indications for endovascular treatment included clinical failure of anticoagulatives or antiplatelet therapy ( 68 patients, 33.8\%), impending risk of stroke (43 patients, $21.4 \%$ ), contraindication for anticoagulatives or antiplatelet therapy (26 patients, $12.9 \%$ ) and expanding pseudoaneurysm formation (15 patients, 7.5\%). In addition, 49 patients $(24.4 \%)$ were treated by emergent endovascular stenting.

\section{Treatment Characteristics}

There were 211 lesions in 201 patients. Of these 211 lesions, 209 were successfully treated with stenting. The technical success rate was $99.1 \%$. Two lesions failed treatment because the guide wire or the stent delivery system failed to cross the true lumen of the vessel owing to occlusion throughout the internal carotid artery. 
Xianjun et al.: A Systematic Review of Endovascular Management of Internal Carotid Artery Dissections

Table 2. Medical treatment after the endovascular intervention

\begin{tabular}{|c|c|}
\hline Authors & Postprocedure medical management \\
\hline Matsuura et al. [8] & aspirin $325 \mathrm{mg} /$ day for 1 year \\
\hline Malek et al. [9] & $\begin{array}{l}\text { ticlopidine (250 mg twice daily) or clopidogrel ( } 75 \mathrm{mg} / \text { day) for } 6 \text { weeks and } \\
\text { aspirin ( } 325 \mathrm{mg} / \text { day) was continued indefinitely }\end{array}$ \\
\hline Tseng et al. [13] & NA \\
\hline Cohen et al. [14] & antiplatelet \\
\hline Fanelli et al. [15] & $\begin{array}{l}\text { low-dose heparin ( } 0.8 \mathrm{ml} / \text { day }) \text { and ticlopidine }(250 \mathrm{mg} / \text { day }) \text { was continued } \\
\text { indefinitely }\end{array}$ \\
\hline Assadian et al. [16] & NA \\
\hline Biggs et al. [17] & clopidogrel and aspirin \\
\hline Cohen et al. [18] & clopidogrel $75 \mathrm{mg} /$ day and aspirin $325 \mathrm{mg} /$ day for 3 months \\
\hline Kadkhodayan et al. [19] & Plavix for 30 days \\
\hline Biondi et al. [20] & NA \\
\hline Briganti et al. [21] & clopidogrel $75 \mathrm{mg} /$ day for 30 days and aspirin was continued indefinitely \\
\hline Edgell et al. [22] & clopidogrel for 6 weeks and aspirin was continued indefinitely \\
\hline Nakagawa et al. [23] & aspirin $325 \mathrm{mg} /$ day for 1 year \\
\hline Fava et al. [24] & $\begin{array}{l}\text { clopidogrel ( } 75 \mathrm{mg} / \text { day) for } 6 \text { weeks and aspirin ( } 325 \mathrm{mg} / \text { day) was continued } \\
\text { indefinitely }\end{array}$ \\
\hline Schulte et al. [25] & clopidogrel for 4 weeks and aspirin was continued indefinitely \\
\hline Surdell et al. [26] & NA \\
\hline Binning et al. [27] & $\begin{array}{l}\text { clopidogrel ( } 75 \mathrm{mg} / \text { day) for } 6 \text { months and aspirin }(325 \mathrm{mg} / \text { day) was continued } \\
\text { indefinitely }\end{array}$ \\
\hline Cohen et al. [28] & clopidogrel $75 \mathrm{mg} /$ day and aspirin $300 \mathrm{mg} /$ day \\
\hline Smith et al. [29] & NA \\
\hline Jeon et al. [30] & $\begin{array}{l}\text { clopidogrel ( } 300 \mathrm{mg} / \text { day) for 3-6 months and aspirin (100-500 mg/day) was } \\
\text { continued indefinitely }\end{array}$ \\
\hline Ohta et al. [11] & clopidogrel for 3 months and aspirin was continued indefinitely \\
\hline Yin et al. [10] & antiplatelet \\
\hline Cohen et al. [6] & $\begin{array}{l}\text { clopidogrel (225-300 mg/day) for 2-3 months and aspirin (100 mg/day) was } \\
\text { continued indefinitely }\end{array}$ \\
\hline
\end{tabular}

NA = Not applicable

One hundred and twenty-five of 209 lesions (59.8\%) were treated with a single stent, while 84 lesions (40.2\%) received multiple stents. In addition, 13 lesions (6.2\%) were treated with stenting followed by coil embolization of an associated pseudoaneurysm. Embolic protection devices (EPD) were used during the treatment of 39 of the 209 lesions (18.7\%).

\section{Postprocedure Medical Management}

Most patients were kept on double antiplatelet therapy for 1-6 months, and single antiplatelet therapy was continued indefinitely. However, the medicines and doses used were different in different reports (table 2).

\section{Complications}

Twelve patients experienced a procedure-related complication; transient vasospasm was observed in 2 patients, intracranial hemorrhage in 2 patients, intimal tear in 2 patients, 
middle cerebral artery (MCA) embolism in 1 patient, worsening of dissection in 1 patient, stent malpositioning in 1 patient, filter retrieval device fracture in 1 patient, retroperitoneal hematoma in 1 patient and embolic protection filter overload in 1 patient. In total, the procedure-related complication rate was $6 \%$. Among these patients, 2 complications caused permanent neurological deficits; there was one case of stroke due to MCA embolism, and in the case of intracranial hemorrhage, the patients died of pneumonia in the hospital.

Four patients experienced an early cerebrovascular event, including transient ischemic attack (TIA) in 3 patients and hemorrhagic conversion in 1 patient. However, these patients recovered satisfactorily. One patient died of an unrelated myocardial infarction (8 days after treatment).

Thus, the overall rate of major cardiovascular events in the perioperative period was $4 \%$ (8 patients).

Follow-Up

Imaging follow-up data (angiography, computed tomography angiography or sonography) were available for 152 patients (76.4\%). The mean follow-up time was 16.5 months (range 1-72 months). During this period, angiography demonstrated mild narrowing of the treated vessel (intimal hyperplasia) in 2 patients, $70 \%$ in-stent restenosis in 1 patient, occlusion of the treated vessel in 2 patients and aneurysm formation in 1 patient. All patients were asymptomatic. Except for these patients above, all of the vessels were patent on followup imaging.

Clinical follow-up data were available for 190 patients (95.5\%). The mean follow-up period was 20.9 months (range 1-92 months). During the follow-up, 3 patients died due to heart transplantation, chronic progressive renal failure and pneumonia (4 months, 7 months and 3 years after stenting, respectively). Four patients suffered recurrent TIA in the territory of the treated vessel $(2.7,3,11$ and 12 months after stenting, respectively). In addition, 1 patient had a stroke in the territory contralateral to the carotid occlusion after hypotensive uterine hemorrhage ( 8 months after stenting). The remaining 182 patients were free of subsequent ischemic symptoms after the procedure.

\section{Discussion}

In the review analysis, we found that endovascular treatment of ICAD had a high technical success rate (99.1\%). The overall major cardiovascular event rate in the perioperative period was low (4\%). No procedure-related deaths occurred. Imaging follow-up data demonstrated that only $3.3 \%$ of patients had intimal hyperplasia, in-stent restenosis or occlusion of the treated vessel and all patients were asymptomatic. Clinical follow-up data showed that only $2.1 \%$ of patients had recurrent TIA in the territory of the treated vessel and no ICAD-related deaths occurred.

Previous studies suggested that most ischemic strokes secondary to ICAD are thromboembolic [4, 31]. Antithrombotic treatment with anticoagulatives or antiplatelets is effective for selected patients. However, in some patients, medical therapy is inadequate $[14,20,24$, $27,32,33]$. In our study, we indicated that endovascular intervention may be a new treatment option. Firstly, endovascular treatment could overcome the several drawbacks of medical therapy. Endovascular strategies could identify true and false lumens. Secondly, endovascular treatment allows the immediate recanalization of the occluded artery and resolution of the dissection [14]. Endovascular treatment can simultaneously alleviate any concomitant pseudoaneurysm formation $[17,19]$. In this study, 49 patients $(24.4 \%)$ were treated by emergent endovascular stenting. Thirteen lesions $(6.2 \%)$ were treated by the placement of 
stents followed by coil embolization of an associated pseudoaneurysm. The procedure was successfully performed in all cases and without procedure-related complications. Finally, routine anticoagulation is not necessary after the procedure. The patients were treated with antiplatelet agents only.

Despite the relative advantages of endovascular intervention in ICAD, no guidelines as to which patients may benefit from such a procedure currently exist. In the review analysis, we suggested that the criteria for stent therapy include the following: (1) patients with recurrent symptoms despite medical therapy, (2) patients with hemodynamic hypoperfusion (involvement of multiple vessels or poor collateral vessels), (3) patients with expanding or symptomatic pseudoaneurysm and (4) contraindication to anticoagulation because of intracranial or systemic hemorrhage.

However, there are some technical difficulties with endovascular treatment. Firstly, selective microcatheterization of the true lumen of the artery is often difficult. Secondly, one of the drawbacks during the procedure was the risk of distal embolization. In our review, 1 patient suffered an MCA embolism that caused permanent neurological deficits. Although EPD are useful for the prevention of this complication, the devices have stiff and bulky tips and it is difficult to navigate them through severely stenotic lesions. Thus, there were some differences in principle in the application of EPD when implementing stent implantation. In the studies included in our review, EPD were used during the treatment of only a few lesions (18.7\%), and there were no cases of distal embolization complications in the remaining patients. Hence, we consider that is it not necessary to use EPD in ICAD patients. However, EPD can be used when dealing with atherosclerotic carotid stenosis. Ohta etal. [11] recommend the use of protection devices for straight and not severely stenotic lesions. Finally, in patients with multiple dissections, the most flow-limiting vessel should be opened initially. Thus, transient vasospasm would not be of clinical significance. Furthermore, if a complication were to occur forcing early termination of the procedure, the most severely affected vessel would already have been repaired.

With regard to the need for postprocedure antiplatelet therapy, it is still a concern. In this review analysis, we found that most patients were kept on double antiplatelet therapy for 1-6 months, and single antiplatelet therapy was continued indefinitely. However, the medicines and doses used were different in different reports. Future prospective studies with large samples are needed in this field.

In addition, the safety and effectiveness of endovascular treatment of intracranial ICAD are still unclear. In our analysis, 24 patients (11.9\%) had intracranial ICAD. The procedure was successfully performed in all the cases, and no clinical complications occurred due to the procedure. To the best of our knowledge, this is the first review to report on endovascular intervention in intracranial ICAD.

Due to the relatively small samples in the previous studies, heterogeneity of the operators, methodological discrepancies and differences in materials used in the procedures may affect the clinical outcomes of these endovascular procedures. In addition, biases may be generated when reporting novel techniques, with a tendency to overestimate the benefits and overlook the disadvantages. Therefore, the results of this present review analysis should be interpreted with caution.

In conclusion, endovascular intervention with stenting or stent-graft-supported angioplasty in selected ICAD is promising. A further randomized controlled study with a large sample and long follow-up is warranted to provide more evidence to support the feasibility of endovascular procedures in treating ICAD. 
Xianjun et al.: A Systematic Review of Endovascular Management of Internal Carotid Artery Dissections

\section{References}

- 1 Debette S, Leys D: Cervical-artery dissections: predisposing factors, diagnosis, and outcome. Lancet Neurol 2009;8:668-678.

- 2 Rao AS, Makaroun MS, Marone LK, et al: Long-term outcomes of internal carotid artery dissection. J Vasc Surg 2011;54:370-375.

- 3 Schievink WI, Mokri B, O’Fallon WM: Recurrent spontaneous cervical-artery dissection. N Engl J Med 1994; 330:393-397.

- 4 Benninger DH, Kremer DG, Studer A, et al: Mechanism of ischemic infarct in spontaneous carotid dissection. Stroke 2004;35:482-485.

- 5 Lyrer P, Engelter S: Antithrombotic drugs for carotid artery dissection. Stroke 2004;35:613-614.

- 6 Cohen JE, Gomori JM, Itshayek E, et al: Single-center experience on endovascular reconstruction of traumatic internal carotid artery dissection. J Trauma Acute Care Surg 2012;72:216-221.

- 7 Beletsky V, Nadareishvili Z, Lynch J, et al: Cervical arterial dissection: time for a therapeutic trial? Stroke 2003; $34: 2856-2860$

- 8 Matsuura JH, Rosenthal D, Jerius H, et al: Traumatic carotid artery dissection and pseudoaneurysm treated with endovascular coils and stent. J Vasc Surg 1997;4:339-343.

- 9 Malek AM, Higashida RT, Phatouros CC, et al: Endovascular management of extracranial carotid artery dissection achieved using stent angioplasty. AJNR Am J Neuroradiol 2000;21:1280-1292.

10 Yin Q, Li Y, Fan X, et al: Feasibility and safety of stenting for symptomatic carotid arterial dissection. Cerebrovasc Dis 2011;32:11-15.

11 Ohta H, Natarajan SK, Hauck EF, et al: Endovascular stent therapy for extracranial and intracranial carotid artery dissection: single-center experience. J Neurosurg 2011;115:91-100.

12 Donas KP, Mayer D, Guber I, et al: Endovascular repair of extracranial carotid artery dissection: current status and level of evidence. J Vasc Interv Radiol 2008;19:1693-1698.

13 Tseng A, Ramaiah V, Rodrigue-Lopez JA, et al: Emergent endovascular treatment of a spontaneous internal carotid artery dissection with pseudoaneurysm. J Endovasc Ther 2003;10:643-646.

14 Cohen JE, Leker RR, Gomori JM, et al: Emergent stenting to treat patients with carotid artery dissection: clinically and radiologically directed therapeutic decision making. Stroke 2003;34:e254-e257.

15 Fanelli F, Salvatori MF, Ferrari R, et al: Stent repair of bilateral post-traumatic dissections of the interna carotid artery. J Endovasc Ther 2004;11:517-521.

16 Assadian A, Senekowitsch C, Rotter R, et al: Long-term results of covered stent repair of internal carotid artery dissections. J Vasc Surg 2004;40:484-487.

17 Biggs KL, Chiou AC, Hagino RT, et al: Endovascular repair of a spontaneous carotid artery dissection with carotid stent and coils. J Vasc Surg 2004;40:170-173.

18 Cohen JE, Ben-Hur T, Rajz G, et al: Endovascular stent-assisted angioplasty in the management of traumatic internal carotid artery dissections. Stroke 2005;36:e45-e47.

19 Kadkhodayan Y, Jeck DT, Moran CJ, et al: Angioplasty and stenting in carotid dissection with or without associated pseudoaneurysm. AJNR Am J Neuroradiol 2005;26:2328-2335.

20 Biondi A, Katz JM, Vallabh J, et al: Progressive symptomatic carotid dissection treated with multiple stents. Stroke 2005;36:e80-e82.

21 Briganti F, Tortora F, Volpe A, et al: Stent implantation for treatment of symptomatic spontaneous cervical internal carotid artery dissecting aneurysm. A case report. Minim Invasive Neurosurg 2005;48:306-309.

-22 Edgell RC, Abou-Chebl A, Yaday JS, et al: Endovascular management of spontaneous carotid artery dissection. J Vasc Surg 2005;42:854-860.

-23 Nakagawa N, Akai F, Fukawa N, et al: Endovascular stent placement of cervical internal carotid artery dissection related to a seat-belt injury: a case report. Minim Invasive Neurosurg 2007;50:115-119.

24 Fava M, Meneses L, Loyola S, et al: Carotid artery dissection: endovascular treatment. Report of 12 patients. Catheter Cardiovasc Interv 2008;71:694-700.

25 Schulte S, Donas KP, Pitoulias GA, et al: Endovascular treatment of iatrogenic and traumatic carotid artery dissection. Cardiovasc Intervent Radiol 2008;31:870-874.

-26 Surdell DL, Bernstein RA, Hage ZA, et al: Symptomatic spontaneous intracranial carotid artery dissection treated with a self-expanding intracranial nitinol stent: a case report. Surg Neurol 2009;71:604-609.

27 Binning MJ, Khalessi AA, Siddiqui AH, et al: Stent placement for the treatment of a symptomatic intracranial arterial dissection in an adolescent. J Neurosurg Pediatr 2010;6:154-158.

28 Cohen JE, Gomori JM, Leker RR, et al: Recanalization of symptomatic carotid artery dissections causing occlusion with multiple stents: the use of delayed double-contrast road map. Neurol Res 2010;32:293-296.

-29 Smith MJ, Santillan A, Segal A, et al: Interventional management for secondary intracranial extension of spontaneous cervical arterial dissection. Surg Neurol Int 2010;1:82.

-30 Jeon P, Kim BM, Kim DI, et al: Emergent self-expanding stent placement for acute intracranial or extracranial internal carotid artery dissection with significant hemodynamic insufficiency. AJNR Am J Neuroradiol 2010; 31:1529-1532.

-31 Srinivasan J, Newell DW, Sturzenegger M, et al: Transcranial Doppler in the evaluation of internal carotid artery dissection. Stroke 1996;27:1226-1230.

-32 Muller BT, Luther B, Hort W, et al: Surgical treatment of 50 carotid dissections: indications and results. J Vasc Surg 2000;31:980-988.

-33 Schievink WI, Piepgras DG, McCaffrey TV, et al: Surgical treatment of extracranial internal carotid artery dissecting aneurysms. Neurosurgery 1994;35:809-815. 